\title{
Statistical Optimization for Biobutanol Production by Clostridium acetobutylicum ATCC 824 from Oil Palm Frond (OPF) Juice Using Response Surface Methodology
}

\author{
Nur Syazana Muhamad Nasrah ${ }^{1}$, Mior Ahmad Khushairi Mohd Zahari ${ }^{1, *}$, Nasratun Masngut ${ }^{1}$ and Hidayah Ariffin ${ }^{2}$ \\ ${ }^{1}$ Faculty of Chemical and Natural Resources Engineering, Universiti Malaysia Pahang, 26300 Gambang, Pahang \\ ${ }^{2}$ Faculty of Biotechnology and Biomelucular Sciences, Universiti Putra Malaysia, 43400 Serdang, Selangor.
}

\begin{abstract}
The interaction between incubation temperature, yeast extract concentration and inoculum size was investigated to optimize critical environmental parameters for production of biobutanol from oil palm frond (OPF) juice by Clostridium acetobutylicum ATCC 824 using response surface methodology (RSM). A central composite design (CCD) was applied as the experimental design and a polynomial regression model with quadratic term was used to analyse the experimental data using analysis of variance (ANOVA). ANOVA analysis showed that the model was very significant $(p<0.0001)$ for the biobutanol production. The incubation temperature, yeast extract concentration and inoculum size showed significant value at $p<0.005$. The results of optimization process showed that a maximum biobutanol production was obtained under the condition of temperature $37{ }^{\circ} \mathrm{C}$, yeast extract concentration $5.5 \mathrm{~g} / \mathrm{L}$ and inoculum size $10 \%$. Under these optimized conditions, the highest biobutanol yield was $0.3054 \mathrm{~g} / \mathrm{g}$ after 144 hours of incubation period. The model was validated by applying the optimized conditions and $0.2992 \mathrm{~g} / \mathrm{g}$ biobutanol yield was obtained. These experimental findings were in close agreement with the model prediction, with a difference of only $9.76 \%$.
\end{abstract}

Keywords: Biobutanol, Response Surface Methodology, Central Composite Design, Oil Palm Frond Juice, Clostridium acetobutylicum (ATCC 824)

\section{Introduction}

Biofuels production has gained interest as an alternative supplies due to the expected rising demand of oil because of the depletion of fossil fuels and increasing oil prices. Biobutanol has been growing more popularity to be one of the alternative biomass fuels since it has many advantageous properties. It has a high energy content, low vapor pressure, less corrosive, can be used directly or blended with gasoline, can be shipped through existing pipelines and can be used in existing engines without any modifications $[1,2]$.

At the moment, agricultural products and wastes such as sugar canes, cassavas, rice straws, corncobs, corn, wheat straw, sweet sorghum, sweet cheese whey, rice bran, date fruit, oil palm trunk sap, and palm oil mill effluent are used as raw materials for the production of butanol [3-14]. Therefore, lignocelluloses, substances commonly found in agricultural wastes, appear to be a feasible resource compare to agricultural products which are used as foods. Since oil palm is one of industrial crops that have been planted extensively throughout the Malaysia, it leads to the increasing amount of palm oil wastes. MPOC (2010) reported that oil palm frond (OPF) is the most generated biomass wastes with 83 million tonnes (wet weight) annually [15]. OPF is available daily because it is obtained during pruning for harvesting fresh fruit bunch (FFB). As for the management of the OPF waste, the pruned fronds are just left in the plantation to be used for nutrient recycling and soil conservation. However, OPF does not contain high metal contents, but it contains high carbohydrates in the form of simple sugar which can be utilized into biobutanol [16]. The renewable sugars from OPF can simply obtained by pressing the fresh OPF to get the juice. The sugars content reported up to $76.09 \mathrm{~g} / \mathrm{L}$ [17].

Therefore, in this study, OPF juice was used as fermentation feedstock by Clostridium acetobutylicum ATCC 824 for production biobutanol. The different strains of Clostridium were used for the production of biobutanol from different lignocellulosic biomass such as $C$. saccharoperbutylicum, and $C$. beijerinckii. However, C. acetobutylicum has been chosen in this study to optimize the environmental parameters of the fermentation process for the biobutanol production.

Response surface methodology (RSM) is one of the most useful statistical optimization tools in biological and chemical process. RSM has been increasingly used for various phases of an optimization process in fermentation. RSM is a collection of statistical and mathematical techniques useful for designing experiments, developing models and evaluating the effects of variables in which a response of interest is influenced by several variables and the objective is to optimize this response. Basically, RSM consists of central composite design (CCD), Box-Behnken design, one factor design, D-optimal design, user-defined design and the historical data design. The most used statistical methods are CCD and Box-Behnken design. For one numeric variable, CCD has 5 levels $(-\alpha,-1,0,+1,+\alpha)$ whereas the Box- Behnken design only has 3 levels $(-1$, $0,+1)$. RSM also provides an experimental model that predicts the correlation and interaction between a set of experimental variables and observed results, and subsequently provides optimized conditions $[18,19]$.

The current research aimed to optimize biobutanol production using RSM with CCD by investigating the

Corresponding author: ahmadkhushairi@ump.edu.my 
effect of inoculum size, incubation temperature, and yeast extract concentration by $C$. acetobutylicum ATCC 824 from OPF juice.

\section{Material and methods}

\subsection{Microorganism and culture media}

Clostridium acetobutylicum ATCC 824 was obtained from American Type Culture Collection (ATCC) in freeze-dried form and maintained in $10 \%$ glycerol stock at $-80^{\circ} \mathrm{C}$. Spore suspension was prepared by transferring $1 \mathrm{~mL}$ of glycerol stock into $90 \mathrm{~mL}$ RCM for 3 days at $37^{\circ} \mathrm{C}$ under anaerobic conditions. Spores were heat shocked for $90 \mathrm{~s}$ in $90^{\circ} \mathrm{C}$ water bath and incubated at $37^{\circ} \mathrm{C}$ under static condition for $18-20 \mathrm{~h} \mathrm{[7]}$. The inoculum was deemed to be ready for fermentation when the optical density was between 1.5 and 2.0.

\subsection{OPF juice preparation}

The oil palm frond (OPF) was obtained from oil palm plantation at Felda Lepar Hilir, Kuantan, Pahang. Malaysia. The OPF was cut into small size and the juice was prepared by pressing the fresh OPF (without leaves) using sugarcane pressing machine by following the previous method described earlier by Zahari et al [16]. $72 \mathrm{~mL}$ of OPF juice was then distributed into $125 \mathrm{ml}$ serum bottles, sparged with oxygen-free nitrogen gas, sealed and sterilized at $121^{\circ} \mathrm{C}$ for 15 minutes. It was then mixed with synthetic P2 medium in known proportion to prepare the final fermentation medium. Synthetic P2 medium had the following composition (in $\mathrm{g} / \mathrm{L}$ ): yeast extract, $5 ; \quad \mathrm{KH}_{2} \mathrm{PO}_{4}, 0.5 ; \quad \mathrm{K}_{2} \mathrm{HPO}_{4}, 0.5 ;$ para aminobenzoic acid, 0.001; thiamin, 0.001; biotin, $1 \times 10^{-5}$; $\mathrm{MgSO}_{4} .7 \mathrm{H}_{2} \mathrm{O}, 0.2 ; \mathrm{MnSO}_{4} .7 \mathrm{H}_{2} \mathrm{O}, 0.01 ; \mathrm{FeSO}_{4} \cdot 7 \mathrm{H}_{2} \mathrm{O}$, $0.01 ; \mathrm{NaCl}, 0.01$; and ammonium acetate, 2.2 [7].

\subsection{Fermentation}

The fermentation was conducted in $125 \mathrm{ml}$ serum bottle containing $100 \mathrm{~mL}$ final volume of the OPF juice, P2 medium and inoculum with different properties depending on the runs based on Table 2, flushed with $\mathrm{N}_{2}$ gas and sterilized at $121^{\circ} \mathrm{C}$ for $15 \mathrm{~min}$. The total sugars concentration and initial $\mathrm{pH}$ conditions were fix with $50 \mathrm{~g} / \mathrm{L}$ and $\mathrm{pH} 6$. Initial $\mathrm{pH}$ of the fermentation broth was adjusted using $2 \mathrm{M} \mathrm{NaOH}$ or $\mathrm{HCl} .15 \mathrm{ml}$ of sample were withdrawn at 0 and $144 \mathrm{hr}$ for analysis of acetone, butanol, ethanol (ABE), organic acids and sugar. The samples were centrifuged at $8,500 \mathrm{rpm}, 4^{\circ} \mathrm{C}$ for $20 \mathrm{~min}$ before analysis.

\subsection{Experimental design and statistical analysis}

A total of twenty (20) experiments were performed according to the range and levels of independent variables, inoculum size, incubation temperature and yeast extract concentration studied for biobutanol production as stated in Table 1. Table 3 shows the experimental design and the results of the response variable studied. The experimental design and analysis of data were done using Design Expert version 7.1 (State-Ease, Inc., Minneapolis, MN).

Table 1. Experimental range and levels of the independent variables.

\begin{tabular}{cccccc}
\hline Independent & \multicolumn{5}{c}{ Range and levels } \\
\cline { 2 - 6 } variables & $-\alpha$ & -1 & 0 & +1 & $+\alpha$ \\
\hline $\begin{array}{c}\text { Temperature } \\
\left({ }^{\circ} \mathrm{C}\right)\end{array}$ & 31 & 34 & 37 & 40 & 43 \\
$\begin{array}{c}\text { Yeast extract } \\
(\mathrm{g} / \mathrm{L})\end{array}$ & 1.5 & 3.5 & 5.5 & 7.5 & 9.5 \\
$\begin{array}{c}\text { Inoculum size } \\
(\%)\end{array}$ & 6 & 8 & 10 & 12 & 14 \\
\hline
\end{tabular}

All experiments were performed in triplicates and the results were recorded as mean values of the biobutanol yield. The biobutanol yield can be expressed as a function of independent variables by a second order polynomial equation:

$$
Y=\beta_{0}+\sum \beta_{0} x_{j}+\sum \beta_{j j} x_{j}^{2}+\sum \beta_{j k} x_{j} x_{k}
$$

where, $\mathrm{Y}$ is the response (biobutanol yield), $\beta_{0} \beta_{\mathrm{j}}, \beta_{\mathrm{jj}}$ and $\beta_{\mathrm{jk}}$ represent the regression coefficient for intercept, linear, quadratic and interaction terms, respectively. Adequacy of the developed model was evaluated by using analysis of variance (ANOVA) technique. The significant terms in the model equation were determined with the help of p-value and F-value and adequacy of model fitting was evaluated by the coefficient of determination $\mathrm{R}^{2}$ and the lack of fit test. Response surfaces and optimum conditions for biobutanol production were obtained through this model.

\subsection{Analytical procedures}

The samples of fermentation were centrifuged at 10,000 rpm and filtered through $0.02 \mu \mathrm{m}$ nylon syringe filter before used for analysis. The products including solvents (acetone, butanol and ethanol) and acids (acetic acid and butyric acid) were analysed by gas chromatography (Agilent Technologies, 6890N network GC system). A microliter of the sample was injected into a $30 \mathrm{~m} \times 0.32$ $\mathrm{mm} \times 0.5 \mu \mathrm{m}$ HP-INNOWAX capillary column at $250^{\circ} \mathrm{C}$. The column carrier was helium, $40 \mathrm{~cm} / \mathrm{sec}, 11.7$ psi $\left(60^{\circ} \mathrm{C}\right)$ with $2.5 \mathrm{ml} / \mathrm{min}$ constant flow. A flame ionization detector (FID) at $275^{\circ} \mathrm{C}$ was used for signal detection. Glucose, sucrose, and fructose were determined by HPLC(Agilent; 1200) with Rezex ROA organic acid $\mathrm{H}+(8 \%)$ column (Phenomenex) $(300 \times 7.80$ $\mathrm{mm}$ ) with a flow rate of $0.5 \mathrm{ml} / \mathrm{min}$ and RI detector at $30^{\circ} \mathrm{C}$. The mobile phase consists of $0.005 \mathrm{M} \mathrm{H}_{2} \mathrm{SO}_{4}$, recommended for the column used.

\section{Results and discussion}




\subsection{Sugars composition of oil palm frond (OPF) juice}

The total sugars concentration of OPF juice was determined by HPLC analysis as shown in Table 2 . The total sugars concentration was $68.58 \mathrm{~g} / \mathrm{L}$. Glucose was found to be dominant sugar $(48.19 \mathrm{~g} / \mathrm{L})$ followed by sucrose $(11.91 \mathrm{~g} / \mathrm{L})$ and fructose $(8.48 \mathrm{~g} / \mathrm{L})$. This result was almost similar with the findings reported by Zahari et al. [16]. They also found that glucose was the dominant sugar in OPF juice followed by sucrose and fructose.

Table 2. Amount of sugar contained in OPF juice

\begin{tabular}{|c|c|c|c|c|}
\hline \multirow{2}{*}{ OPF juice } & \multicolumn{3}{|c|}{ Sugar $(\mathrm{g} / \mathrm{L})$} & Total sugar \\
\cline { 2 - 4 } & Glucose & Fructose & Sucrose & $(\mathrm{g} / \mathrm{L})$ \\
\hline Sample 1 & 47.78 & 8.37 & 11.78 & 67.93 \\
\hline Sample 2 & 48.60 & 8.58 & 12.04 & 69.22 \\
\hline Average & 48.19 & 8.48 & 11.91 & 68.58 \\
\hline
\end{tabular}

However, Zahari et al. [16] showed slightly higher total sugars concentration $(76.09 \mathrm{~g} / \mathrm{L})$ compared to this study where sugars composition was reported as; $68.58 \mathrm{~g} / \mathrm{L}$. This might be due to the different location of collecting the OPF. The OPF in this work was obtained from the oil palm plantation in Gambang, Pahang, meanwhile Zahari et al. [16] obtained from Serdang, Selangor.

\subsection{Model equation for biobutanol production}

Inoculum size, temperature, and yeast extract concentration were optimized by central composite design (CCD) of RSM around the ranges as shown in Table 1. The mathematical relationship for the biobutanol production from OPF juice by $C$. acetobutylicum ATCC 824 was developed by considering three independent variables: temperature, yeast extract concentration and inoculum size; and one dependent variable: biobutanol yield obtained from per gram biobutanol concentration per sugars concentration consumption. The respective models are shown below:

$\mathrm{Y}=+0.27+0.017 * \mathrm{~A}-0.030 * \mathrm{~B}+0.025 * \mathrm{C}-0.014 *$ $\mathrm{A} * \mathrm{~B}+4.388 \mathrm{E}-003 * \mathrm{~A} * \mathrm{C}-0.012 * \mathrm{~B} * \mathrm{C}-0.046 *$ $\mathrm{A}^{2}-0.049 * \mathrm{~B}^{2}-0.037 * \mathrm{C}^{2}$

where $\mathrm{Y}$ is biobutanol yield, $\mathrm{A}$ is inoculum size, $\mathrm{B}$ is temperature and $\mathrm{C}$ is yeast extract concentration. The quadratic model was selected to provide the best fit with the experimental results. Eq. (2) was formulated using the complete experimental design and response matrix through Table 3 and Eq. (1). Analysis of variance for response surface quadratic model and parametric conditions for validating the model of biobutanol production process were represented in Tables 4 and 5 respectively.

\subsection{Analysis of variance (ANOVA) of biobutanol production model}

The results obtained by CCD were analysed by standard analysis of variance (ANOVA) as in Table 4. Regression analysis indicated a coefficient of determination $\left(\mathrm{R}^{2}\right)$ of 0.9497 explaining that approximately $94.97 \%$ of the variability in the response, as well as a high value of the adjusted determination coefficient (adjusted $\mathrm{R}^{2}=$ 0.9044). It indicated a good agreement between experimental and predicted values. From Table 4, it was clearly shows that the model was statistically significant regarding highest F-value of 20.97 , very low probability value $(p<0.0001)$ and sum of square of 0.14 . It was also observed that all the linear $(\mathrm{A}, \mathrm{B}$ and $\mathrm{C})$ and quadratic $\left(A^{2}, B^{2}\right.$ and $\left.C^{2}\right)$ coefficients were significant on biobutanol production as the $\mathrm{p}$-values calculated for this factor was less than 0.05 . Therefore, changes in this parameter could significantly impact the biobutanol production from OPF juice fermentation. Meanwhile, all the interaction coefficients were insignificant; indicating that these terms had little impact on butanol production. The most significant effect of the linear coefficients is temperature (B), followed by yeast extract concentration (C) and inoculum size (A). Generally, the lack of fit pvalue of 0.7229 implied that the lack of fit is not significant relative to the pure error. The non-significant lack of fit is positive because it demonstrates a good fit of the model to the data. A good fit means that the generated models adequately explained the variation of data. The actual vs. predicted and residuals vs. predicted responses are shown respectively in Fig. 1 and 2.

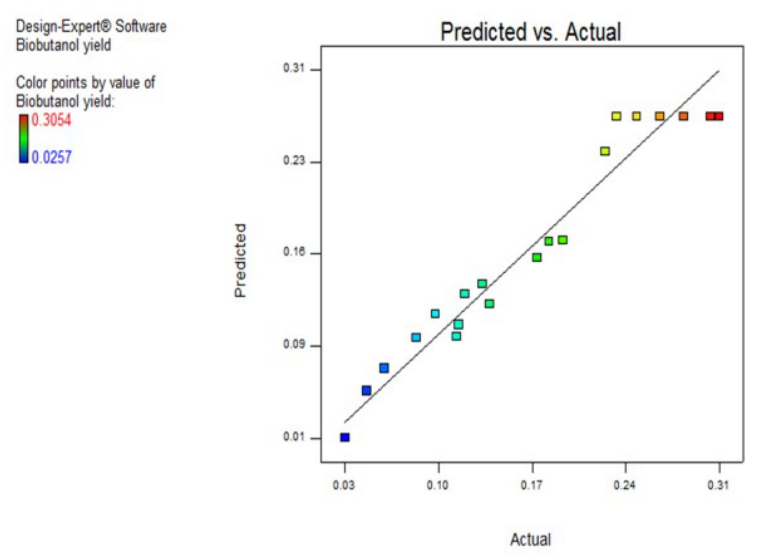

Fig. 1. Actual vs. predicted response of biobutanol production.

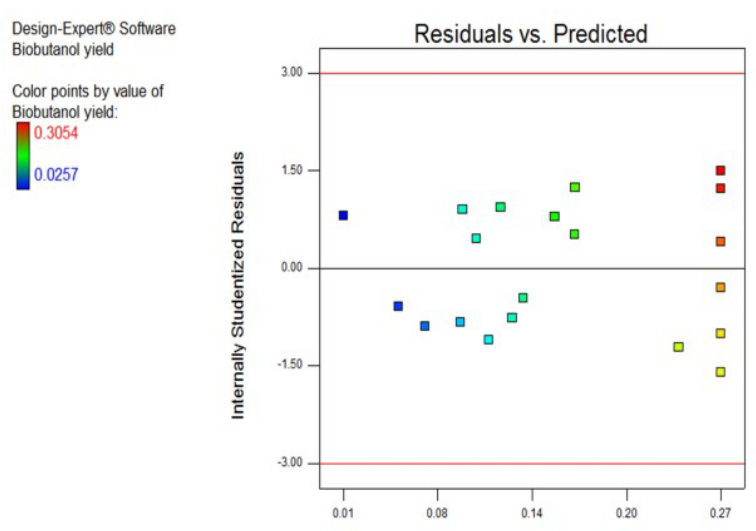

Fig. 2. Residual plot of biobutanol production. 
Table 3. Experimental design matrix using RSM with CCD and response for biobutanol production.

\begin{tabular}{cccccc}
\hline Run No. & \multicolumn{2}{c}{ Variables } & \multicolumn{2}{c}{ Response } \\
\cline { 2 - 5 } & Inoculum size & Temperature & Yeast extract & \multicolumn{2}{c}{ Biobutanol yield (g/g) } \\
\cline { 2 - 6 } & $(\%)$ & $\left({ }^{\circ} \mathrm{C}\right)$ & 3.5 & Experimental value & Predicted value \\
\hline 1 & 8 & 34 & 3.5 & 0.1107 & 0.1000 \\
2 & 12 & 34 & 3.5 & 0.1094 & 0.1600 \\
3 & 8 & 40 & 3.5 & 0.0789 & 0.0940 \\
4 & 12 & 40 & 7.5 & 0.1781 & 0.0930 \\
5 & 8 & 34 & 7.5 & 0.2199 & 0.1700 \\
6 & 12 & 34 & 7.5 & 0.0932 & 0.2400 \\
7 & 8 & 40 & 7.5 & 0.1150 & 0.1100 \\
8 & 12 & 40 & 5.5 & 0.0419 & 0.1300 \\
9 & 6 & 37 & 5.5 & 0.1339 & 0.0510 \\
10 & 14 & 37 & 5.5 & 0.1282 & 0.1200 \\
11 & 10 & 31 & 5.5 & 0.0257 & 0.1400 \\
12 & 10 & 43 & 1.5 & 0.0551 & 0.0130 \\
13 & 10 & 37 & 9.5 & 0.1887 & 0.0690 \\
14 & 10 & 37 & 5.5 & 0.2289 & 0.1700 \\
15 & 10 & 37 & 5.5 & 0.3054 & 0.2700 \\
16 & 10 & 37 & 5.5 & 0.2786 & 0.2700 \\
17 & 10 & 37 & 5.5 & 0.2437 & 0.2700 \\
18 & 10 & 37 & 5.5 & 0.2986 & 0.2700 \\
19 & 10 & 37 & 5.5 & 0.2611 & 0.2700 \\
20 & 10 & 37 & & & 0.2700 \\
\hline
\end{tabular}

Table 4. Analysis of variance (ANOVA) for the experimental results of CCD quadratic model.

\begin{tabular}{|c|c|c|c|c|c|c|}
\hline Source & Sum of square & DF & Mean square & F Value & Prob $>F$ & \\
\hline Model & 0.14 & 9 & 0.015 & 20.97 & $<0.0001$ & Significant \\
\hline $\begin{array}{c}\text { A : Inoculum } \\
\text { size }\end{array}$ & $4.76 \mathrm{E}-003$ & 1 & $4.76 \mathrm{E}-003$ & 6.59 & 0.0281 & \\
\hline B : Temperature & 0.015 & 1 & 0.015 & 20.48 & 0.0011 & \\
\hline$C:$ Yeast extract & 0.010 & 1 & 0.010 & 14.19 & 0.0037 & \\
\hline $\mathrm{AB}$ & $1.482 \mathrm{E}-003$ & 1 & $1.482 \mathrm{E}-003$ & 2.05 & 0.1828 & \\
\hline $\mathrm{AC}$ & $1.540 \mathrm{E}-004$ & 1 & $1.540 \mathrm{E}-004$ & 0.21 & 0.6544 & \\
\hline $\mathrm{BC}$ & $1.193 \mathrm{E}-003$ & 1 & $1.193 \mathrm{E}-003$ & 1.65 & 0.2280 & \\
\hline $\mathrm{A}^{2}$ & 0.053 & 1 & 0.053 & 72.92 & $<0.0001$ & \\
\hline $\mathrm{B}^{2}$ & 0.059 & 1 & 0.059 & 81.89 & $<0.0001$ & \\
\hline $\mathrm{C}^{2}$ & 0.035 & 1 & 0.035 & 48.36 & $<0.0001$ & \\
\hline Residual & 7.234E-003 & 10 & 7.234E-004 & & & \\
\hline Lack of fit & 2.631E-003 & 5 & $5.262 \mathrm{E}-004$ & 0.57 & 0.7229 & Not significant \\
\hline Pure error & 4.603E-003 & 5 & $9.206 \mathrm{E}-004$ & & & \\
\hline Cor total & 0.14 & 19 & & & & \\
\hline \multicolumn{2}{|c|}{ Standard deviation $=0.027$} & \multicolumn{2}{|c|}{ PRESS $=0.028$} & \multicolumn{3}{|c|}{ Pred $\mathrm{R}^{2}=0.8077$} \\
\hline \multicolumn{2}{|c|}{ Mean $=0.16$} & \multicolumn{2}{|c|}{$\mathrm{R}^{2}=0.9497$} & \multicolumn{3}{|c|}{ Adequate precision $=13.409$} \\
\hline \multicolumn{2}{|c|}{ C. V. $\%=16.48$} & \multicolumn{5}{|c|}{ Adjusted $\mathrm{R}^{2}=0.9044$} \\
\hline
\end{tabular}

The actual vs. predicted responses exhibit almost a linear relationship which predicts the reasonable precision of fitted empirical model. Residuals vs. predicted responses in Fig. 2 represent unusual structure and equally scattered points above and below the $\mathrm{x}$-axis but all these points are between \pm 3.0 which imply adequacy and reliability of proposed models. Hence, it can be resolved that developed models are adequate in predicting biobutanol production from OPF juice by $C$. acetobutylicum ATCC 824.

Corresponding author: ahmadkhushairi@ump.edu.my 


\subsection{Parametric interaction effect}

Evaluations of the interactions between various factors using RSM quantifies in terms of three dimensional response surfaces and contour lines. Figure 3, 4 and 5 were plotted to demonstrate the interactions among the three factors and to estimate biobutanol yield over the independent variables. These plots demonstrate the effects of two factors on the response at a time and assist in arbitration of degree of parametric interactions on the desired responses. Three response surfaces were generated depending on three variables involved in the process. Fig. 3 shows three dimensional response surface relationships between inoculum size and temperature on the biobutanol production at the center level of the fermentation temperature. It can be observed that biobutanol yield increases with increasing of inoculum size and the temperature has no steeper effect on biobutanol production.

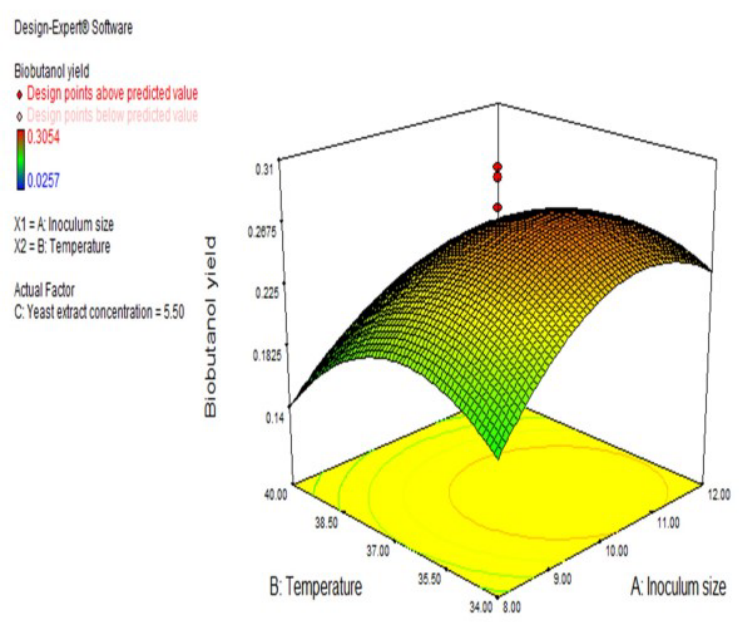

Fig. 3. Response surface and contour plot showing the effect of inoculum size and temperature on biobutanol yield.

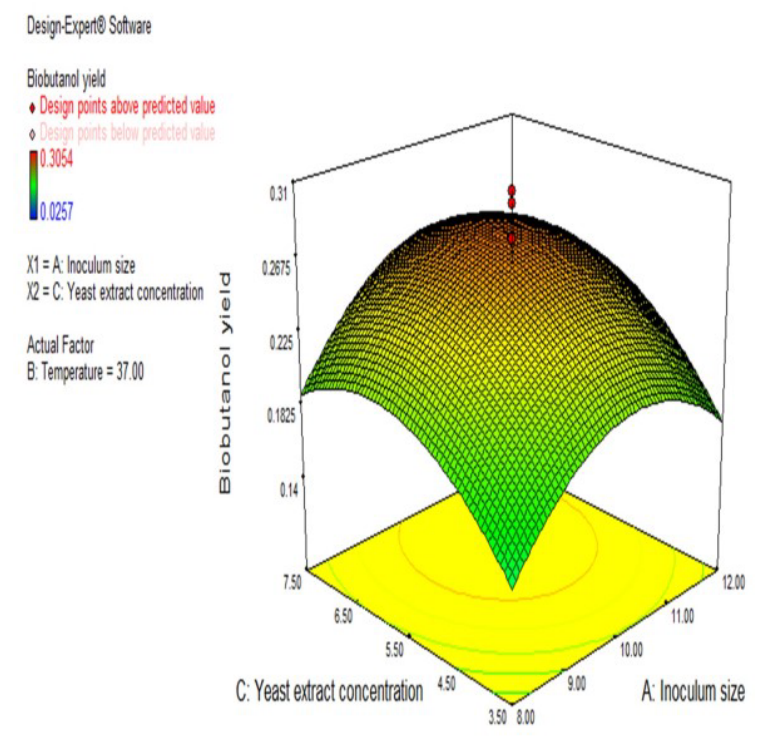

Fig. 4. Response surface and contour plot showing the effect of inoculum size and yeast extract concentration on biobutanol yield.

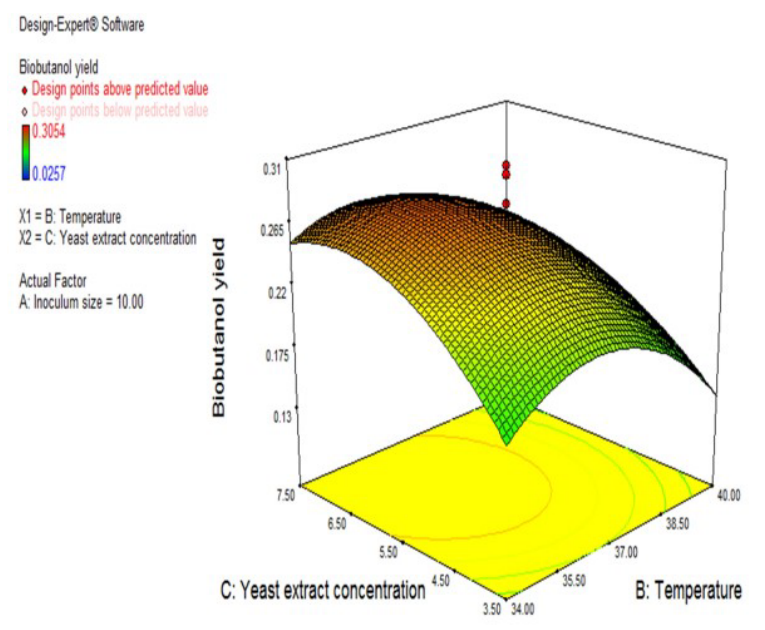

Fig. 5. Response surface and contour plot showing the effect of temperature and yeast extract concentration on biobutanol yield.

The three dimensional response surface relationships between inoculum size and yeast extract concentration at the center level of reaction time is illustrated in Fig. 4. It can be seen that biobutanol yield increases with increasing of inoculum size and yeast extract concentration. Biobutanol yield then reaches to a maximum point and again starts decrease with increasing the yeast extract concentration. Fig. 5 displays three dimensional response surface interactions between temperature and yeast extract concentration at the center level of biobutanol yield. It is evident that biobutanol production increasing with increasing of yeast extract concentration but it reduces with rising the temperature. The effects of temperature and yeast extract concentration on biobutanol yield are more significant than inoculum size. From Fig. 3 and 5, it can be observed that there were very low biobutanol productions at high temperature. This phenomenon happened could be attributed to the fact that high temperature inhibits enzyme catalysed reactions that are essential for cellular metabolism of acid and solvent production in ABE fermentation [21].

\subsection{Optimization of biobutanol production}

The model generated from experimental results (Table 3) represented maximum biobutanol yield is at the center point conditions with temperature $37^{\circ} \mathrm{C}$, yeast extract concentration $5.5 \mathrm{~g} / \mathrm{L}$ and inoculum size $10 \%$. At these conditions, the biobutanol yield is up to $0.3054 \mathrm{~g} / \mathrm{g}$.

The optimum inoculums size is varied depending upon the microorganism and substrate used. A study was found by Al-Shorgani et al. (2015), who observed that the maximum butanol production by $C$. saccharoperbutylacetonicum N1-4 (ATCC 13564) from palm oil mill effluent in ABE fermentation is at an optimum inoculum size of $15 \%$ [20]. On the other hand, the production of butanol by $C$. acetobutylicum MTCC 481 from rice straw hydrolysate was investigated by Ranjan et al. (2013) and they found that an inoculum size of 5\% was the optimum inoculum size [21]. Besides 
that, studies performed by Razak et al. (2013) revealed that the maximum butanol production by $C$. acetobutylicum from oil palm decanter cake hydrolysate in $\mathrm{ABE}$ fermentation was achieved at an optimum inoculum size of $16.2 \%(\mathrm{v} / \mathrm{v})$ [22]. The improving butanol production with the increasing inoculum size due to the fact that is because of an increase in the inoculation of Clostridial cells decreases the lag phase of microbial cell growth. This condition improves Clostridial growth resulting in the enhancement of solventogenesis phase and also the butanol production [23]. As can be seen in Fig. 3 and 4, increasing the inoculum size higher than the critical level of $10 \%$ did not show an improvement in butanol production. This phenomenon can be related to the fact that an increase in the inoculum size more than the critical level (optimum value) had no considerable effects on lag phase of microbial growth and cell activity, which resulted in the production of biobutanol [21].

The optimum incubation temperature in this study is observed at $37^{\circ} \mathrm{C}$. A similar pattern was observed by $\mathrm{Ni}$ et al. (2013) who cultivated Clostridium saccharobutylicum DSM 13864 using cane molasses found the optimum temperature for maximum butanol synthesis was $37^{\circ} \mathrm{C}$ [24]. Studies performed by Sheng et al. (2011) and Khamaiseh et al. (2013) showed that the highest butanol production by $C$. acetobutylicum from corn straw hydrolysate and date fruit medium was detected at incubation temperature of $35^{\circ} \mathrm{C}[25,26]$. The optimum incubation temperature is varied depending upon the microorganism and substrate used.

Yeast extract, enriched with nitrogen sources as proteins and amino acids, is one of the common used nitrogen sources for cell culture and fermentation processes which can promote phase shift from acidegonesis to solventogenesis and indirectly enhance biobutanol production. It was reported that the addition of yeast extract could promote phase shift occurrence and improve fermentation by $C$. acetobutylicum ATCC 824 performances comprehensively when using cassava substrate as high as $80 \%$ of productivity [27]. In this study, the maximum biobutanol yield by $C$. acetobutylicum ATCC 824 from OPF juice was produced at $5.5 \mathrm{~g} / \mathrm{L}$ yeast extract concentration (Table 3 ). This result similar to the study reported by Madihah et al. (2001) who observed $0.34 \mathrm{~g} / \mathrm{g}$ biobutanol yield by C.acetobutylicum from gelatinized sago starch with additional $5 \mathrm{~g} / \mathrm{L}$ of yeast extract in the substrate [28]. Ibrahim et al. (2012) also reported that the ABE production by $C$. butyricum EB6 using oil palm empty fruit bunch as alternative substrate with supplemented basal medium which consisted $6 \mathrm{~g} / \mathrm{L}$ of yeast extract produce as high as $0.24 \mathrm{~g} / \mathrm{g}$ of ABE yield [29]. Therefore, yeast extract can stimulate the growth of the cells, resulting in increasing the cells to produce the solvents. However, as Fig. 3 and 5, at too high yeast extract concentration, more than $5.5 \mathrm{~g} / \mathrm{L}$, the production seems to be decreasing. This is because of the extensive sugar consumption by the cells in the growth phase that make the reduction in cells to produce the solvents.

\subsection{Validation of biobutanol optimization}

To further validate the accuracy of RSM prediction, an experiment was performed under the optimal conditions obtained from Table 3. This validation was also used to verify the accuracy of the model. Validation was carried out under conditions as follows: temperature $37^{\circ} \mathrm{C}$, the yeast extract concentration $5.5 \mathrm{~g} / \mathrm{L}$ and the inoculum size $10 \%$. Under the above optimized condition, the maximum production of biobutanol was estimated as $0.27 \mathrm{~g} / \mathrm{g}$. The results were verified by triplicate experiments and the maximum butanol yield was 0.3012 $\mathrm{g} / \mathrm{g}$ was obtained from the validation test (Table 5). These experimental findings were in close agreement with the model prediction, with a difference of only $9.76 \%$. This validated that the RSM approach was effective for optimizing the operational conditions for the $\mathrm{ABE}$ fermentation process.

Table 5. Model validation of the biobutanol production.

\begin{tabular}{lrc}
\hline Parameters & & Value \\
\hline Inoculum size $(\%)$ & & 10 \\
Temperature $\left({ }^{\circ} \mathrm{C}\right)$ & 37 \\
Yeast extract $(\mathrm{g} / \mathrm{L})$ & & 5.5 \\
Biobutanol yield $(\mathrm{g} / \mathrm{g})$ & Predicted & 0.2700 \\
& Actual & 0.2992 \\
\hline
\end{tabular}

\section{Conclusions}

Using RSM based on CCD model, optimum conditions for biobutanol production from OPF juice by $C$. acetobutylicum ATCC 824 were; inoculum size 10\%, incubation temperature $37^{\circ} \mathrm{C}$ and yeast extract concentration $5.5 \mathrm{~g} / \mathrm{L}$. The interactions between the factors can be observed that biobutanol yield increases with increasing of temperature, inoculum size and yeast extract concentration and reach to the maximum point which are the optimum conditions for the fermentation process. The linear and quadratic effects of inoculum size, temperature and yeast extract concentration are significant. The maximum biobutanol production observed was $0.2992 \mathrm{~g} / \mathrm{g}$ of biobutanol yield.

The authors are grateful to Universiti Malaysia Pahang for financial support (grant numbers RDU 140139).

\section{References}

1. P. Durre, Fermentative production of butanol the academic perspective, Current Opinion in Biotechnology 22, 331-336 (2011)

2. S. Y. Lee, J. H. Park, S. H. Jang, L. K. Nielsen, J. Kim, K. S. Jung, Fermentative butanol production by clostridia, Biotechnology and Bioengineering 101, 2 (2008)

3. W. Jiang, J. Zhao, Z. Wang, S. T. Yang, Stable high-titer n-butanol production from sucrose 
and sugarcane by Clostridium acetobutylicum JB200 in repeated batch fermentation, Bioresource Technology 163, 172-179 (2014)

4. Y. Gu, S. Hu, J. Chen, L. Shao, H. He, Y. Yang, S. Yang, W. Jiang, Ammonium acetate enhances solvent production by Clostridium acetobutylicum EA 2018 using cassava as a fermentation medium, J Ind Microbial Biotechnol 36, 1225-1232 (2009)

5. L. D. Gottumukkala, B. Parameswaran, S. K. Valappil, K. Mathiyazhakan, A. Pandey, R. K. Sukumaran, Biobutanol production from rice straw by a non acetone producing Clostridium sporogenes BE01, Bioresource Technology 145, 182-187 (2013)

6. M. Kumar, D. Kumar, B. Singh, Utilization of agro residue corncob for production of acetonebutanol using Clostridium acetobutylicum and process optimization through RSM, J Microbial Biochem Technol S8, 005 (2014)

7. N. Qureshi, H. P. Blaschek, ABE production from corn: a recent economic evaluation, Journal of Industrial Microbiology \& Biotechnology 27, 292-297 (2001)

8. C. Bellido, M. L. Pinto, M. Coca, G. G. Benito, M. T. G. Cubero, Acetone-butanol-ethanol (ABE) production by Clostridium beijerinckii from wheat straw hydrolysates: Efficient use of penta and hexa carbohydrates 167, 198-205 (2014)

9. B. Ndaba, I. Chiyanzu, S. Marx, Direct fermentation of sweet sorghum juice by Clostridium acetobutylicum and Clostridium tetanomorphum to produce bio-butanol and organic acids, Biofuel Research Journal 6, 248252 (2015)

10. M. Becerra, M. E. Cerdan, M. I. G. Siso, Biobutanol from cheese whey, Microbial Cell Factories 14, 27 (2015)

11. N. K. N. Al-Shorgani, M. S. Khalil, W. M. W. Yusoff, Biobutanol production from rice bran and de-oiled rice bran by Clostridium saccharoperbutylacetonicum N1-4, Bioprocess Biosyst. Eng. 35, 817-826 (2012)

12. E. I. Khamaiseh, M. S. Kalil, E. Ali, A. A. Hamid, W. M. W. Yusoff, Biobutanol production by Clostridium acetobutylicum NCIMB 13357 in modified medium using date fruit as a carbon source, Jordon International Energy Conference (2011)

13. I. Komonkiat, B. Cheirsilp, Felled oil palm trunk as a renewable source for biobutanol production by Clostridium spp., Bioresource Technology 146, 200-207 (2013)
14. M. S. Kalil, P. W. Kit, W. M. W. Yusoff, Y. Sadazo, R. A. Rahman, Direct fermentation of palm oil mill effluent to acetone-butanolethanol by solvent producing Clostridia, Pakistan Journal of Biological Sciences 6, 14 (2003)

15. MPOC, Palm Oil: A Success Story in Green Technology Innovations. http://www.akademisains.gov.my/download/as mic/asmic2010/Plenary12.pdf (2011)

16. M. A. K. M. Zahari, S. S. S. Abdullah, A. M. Roslan, H. Ariffin, Y. Shirai, M. A. Hassan, Efficient utilization of oil palm frond for biobased products and biorefinery, Journal of Cleaner Production 65, 252-260 (2014)

17. M. A. K. M. Zahari, M. R. Zakaria, H. Ariffin, M. N. Mokhtar, J. Salihon, Y. Shirai, M. A. Hassan, Renewable sugars from oil palm frond juice as an alternative novel fermentation feedstock for value-added products, Bioresource Technology 110, 566-571 (2012)

18. M. A. Bezerra, R. E. Santelli, E. P. Oliveira, L. S. Villar, L. A. Escaleira, Response surface methodolody (RSM) as a tool for optimization in analytical chemistry, Talanta 76, 965-977 (2008)

19. D. Bas, I. H. Boyac, Modeling and optimization I: usability of response surface methodology, J. Food Eng. 78, 836-845 (2007)

20. N. K. N. Al-Shorgani, H. Shukor, P. Abdeshahian, M. Y. M. Nazir, M. S. Kalil, A. A. Hamid, W. M. W. Yusoff, Process optimization of butanol production by Clostridium saccharoperbutylacetonicum N1-4 (ATCC 13564) using palm oil mill effluent in acetone-butanol-ethanol fermentation, Biocatalysis and Agricultural Biotechnology 4, 244-249 (2015)

21. A. Ranjan, S. Khanna, V. S. Moholkar, Feasibility of rice straw as alternate substrate for biobutanol production, Applied Energy 103, 32-38 (2013)

22. M. N. A. Razak, M. F. Ibrahim, P. L. Yee, M. A. Hassan, S. A. Aziz, Statistical optimization of biobutanol production from oil palm decanter cake hydrolysate by Clostridium acetobutylicum ATCC 824, BioResource 8, 2 (2013)

23. H. Shukor, N. K. N. Al-Shorgani, P. Abdeshahian, A. A. Hamid, N. Anuar, N. A. Rahman, M. S. Kalil, Production of butanol by Clostridium saccharoperbutylacetonicum N1-4 from palm kernel cake in acetone-butanol- 
ethanol fermentation using empirical model, Bioresource Technology 170, 565-573 (2014)

24. Y. Ni, Z. Xia, Y. Wang, Z. Sun, Continuous butanol fermentation from inexpensive sugarbased feedstocks by Clostridium saccharobutylicum DSM 13864, Bioresource Technology 129, 680-685 (2013)

25. L. Y. Sheng, W. Jing, W. X. Ming, S. X. Hong, Optimization of butanol production from corn straw hydrolysate by Clostridium acetobutylicum using response surface method, Chinese Sci. Bull. 56, 1422-1428 (2011)

26. E. I. S. Khamaiseh, A. A. Hamid, W. M. W. Yusoff, M. S. Kalil, Effect of some environmental parameters on biobutanol production by Clostridium acetobutylicum NCIMB 13357 in date fruit medium, Pakistan Journal of Biotechnology Sciences 16, 20 (2013)

27. X. Li, Z. Li, J. Zheng, Z. Shi, L. Li, Yeast extract promotes phase shift of bio-butanol fermentation by Clostridium acetobutylicum ATCC 824 using cassava as substrate, Bioresource Technology 125, 43-51 (2012) 